\title{
The NPS MedicineWise vision for Australian Prescriber
}

\section{Lynn Weekes AM \\ Chief executive officer NPS MedicineWise Sydney}

\section{Keywords \\ Australian Prescriber, medical journal}

Aust Prescr 2016;39:70-1

http://dx.doi.org/10.18773/ austprescr.2016.042

\begin{abstract}
Australian Prescriber is much loved by you, its readers, and justifiably so. You have said in many readership surveys over the years that you value the quality of the content and the concise easy-to-read format. I know that you appreciate the 'without fear or favour' approach the journal takes, on both clinical and policy matters.
\end{abstract}

Some 53000 health professionals receive Australian Prescriber including about 12000 GPs, 9000 medical specialists and 14000 pharmacists. It is popular internationally and the website has had a high rate of hits.

So why has NPS MedicineWise decided to make changes to this icon of Australian medical publishing and why now? It could be seen as a contentious decision and requires scrutiny because the future of Australian Prescriber is something we all care about. NPS MedicineWise has been the custodian of the

\section{From the Editor}

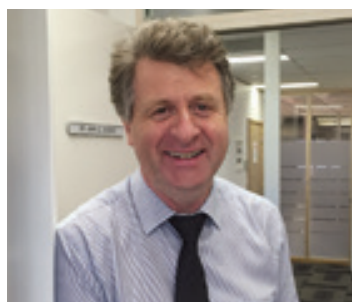

After more than 40 years, this is the final print issue of Australian Prescriber.

When launching Australian Prescriber in 1975, the then Minister of Health said that the journal would aspire to fill a gap in the availability of balanced, impartial, reliable and up-to-date information. Nowadays people have access to so much information that there is a problem of information overload. To overcome this problem, Richard Day and Leone Snowden provide a list of useful sources of drug information.

The Editorial Executive Committee hopes the poster on swapping antidepressants will be another helpful resource. Nicholas Keks, Judy Hope and Simone Keogh explain the prescribing principles behind switching and stopping these drugs.

Compared to 1975, there are now many more medicines available and medical advances are producing innovative, but expensive, new drugs. Charles Denaro and Jennifer Martin consider the challenge of costly drugs.

Advances in technology also make it easier to investigate patients. While bone biopsy might have been used in 1975, Angela Sheu and Terry Diamond tell us that it is now rarely needed in the diagnosis of secondary osteoporosis.

Another challenge for today is the increase in the misuse of prescription drugs. Jenny James gives advice on dealing with drug-seeking behaviour.

As this edition is important in the history of Australian Prescriber, it is appropriate that Lynn Weekes explains her decision to stop print publication and to outline the vision for the journal within NPS MedicineWise. The end of print will also see the end of indexing. In addition to farewelling the staff at CanPrint Communications, the editorial team would like to thank Paul Hodgson who has indexed Australian Prescriber since 1992. journal since 2002 and we know it is one of our most valuable products.

At 40 years old, the journal remains as vital and effective as at inception. It has retained its relevance over the years by being connected with the readers, adapting to change and regularly introducing innovations. Australian Prescriber was one of the first Australian medical journals to go online. It was early to introduce mobile access and last year it produced its first app, The Doctor's Bag.

Australian Prescriber is run very efficiently by a small team of passionate and talented people. It has a thorough editorial process that adds tremendous value to the articles it commissions. It has strong and enduring relationships with some of the best medical and pharmacy minds in the country. I believe these three key components are critical to the quality, credibility and utility of Australian Prescriber. These are the things that I trust will never be compromised. However, maintenance of these critical features of Australian Prescriber's operations sits on a background of gradually increasing costs and a slightly smaller funding envelope for NPS MedicineWise in the coming years. We want to continue to innovate, grow the readership and keep pace with changes in medical publishing, and to succeed we need to reallocate resources.

On this basis, I have taken the decision to cease print publication and distribution. While I know many readers will miss the hard copy, I encourage you to tell us what formats will work best for you in a digital world. In 2012, doctors were spending an average of six hours per week online and had high levels of access to computers, tablets and smart phones. ${ }^{1}$ An NPS MedicineWise survey in 2012 found that $55 \%$ of GPs prefer to do self-education online. ${ }^{2}$ More recent data from the wider community would lead us to believe this connectivity has increased. A Nielson poll in December 2015 reported that over 18 million Australians use the internet. They spend 30 hours on average per week online and the growing areas of use are mobile phones and tablets, now making up $69 \%$ of all use. ${ }^{3}$

The future for Australian Prescriber is bright. It will remain an important medical journal here and internationally. One of the early challenges will be to increase email subscriptions to reach existing 


\section{<ustralian Prescriber}

VOLUME 39 : NUMBER 3 : JUNE 2016

readers and also find new readers. For example, our circulation numbers show that not all GPs have signed up to receive Australian Prescriber in print. I hope we can move towards $100 \%$ of GPs reading the journal online.

Making the journal available when and how readers find most convenient is likely to mean expanding to some new media formats. The Australian Prescriber team will be undertaking evaluation to learn more about the best ways to bring digital content to you, whatever your needs.
There will be opportunities to bring articles together to support students and practitioners with particular questions or needs. The journal will also be looking for ways to support new prescribers, whatever their profession.

Australian Prescriber will continue to be essential reading for everyone wanting to stay up to date with drugs and therapeutics. $\varangle$

Conflict of interest: Lynn Weekes is the chief executive officer of NPS MedicineWise.

\section{REFERENCES}

1. Manhattan Research. Taking the Pulse Australia 2012 Burlington (MA): DRG; 2013 Feb 12.

https://decisionresourcesgroup.com/report/4651 [cited 2016 May 1]

2. Yee M, Simpson-Young V, Paton R, Zuo Y. How do GPs want to learn in the digital era? Aust Fam Physician 2014;43:399-402
3. Nielsen's Australian Online Landscape Review. Interactive and PDF - Dec 2015. Sydney: IAB Australia; 2016 Jan 19. www.iabaustralia.com.au/research-and-resources/researchresources/item/12-research-and-resource/2035-australianonline-landscape-review-interactive-and-pdf-dec-2015 [cited 2016 May 1]

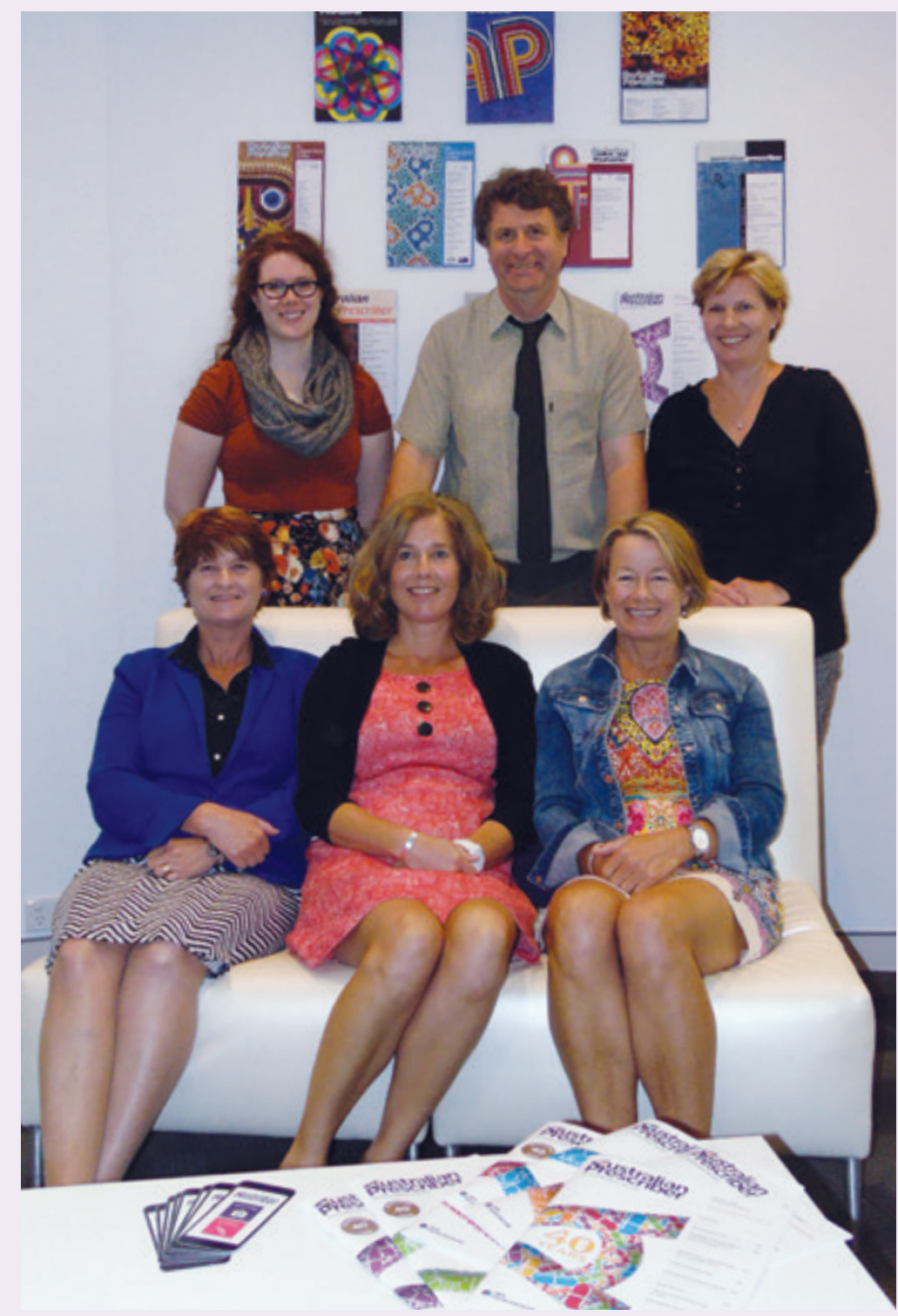

The Australian Prescriber team for the final print issue

Back row, left to right: Kathleen McGarry (Production coordinator), Dr John Dowden (Editor), Jennifer Dixon (Office administrator). Front row: Cherie Graham (Editorial assistant), Dr Fiona Mackinnon (Deputy editor), Georgina Hickey (Production manager). 